\title{
DIAGNÓSTICO SOCIAL, AMBIENTAL, TÉCNICOS E ECONÔMICOS DE UMA UNIDADE DE PRODUÇÃO AGRÍCOLA
}

\section{ARTIGO ORIGINAL}

SILVA, Jean Augusto Bueno da ${ }^{1}$, JEZIORSKI, Cleiton Luís², MELLER, Júlio César³, KREUTZ, Ivar José

SILVA, Jean Augusto Bueno da. Et al. Diagnóstico social, ambiental, técnicos e econômicos de uma unidade de produção agrícola. Revista Científica Multidisciplinar Núcleo do Conhecimento. Ano. 07, Ed. 02, Vol. 02, pp. 54-77. Fevereiro de 2022. ISSN: 2448-0959, Link de acesso: https://www.nucleodoconhecimento.com.br/agronomia/producao-agricola

\section{RESUMO}

O agronegócio vem se desenvolvendo cada vez mais através de técnicas que maximizam e facilitam o desenvolvimento de boas práticas agropecuárias, as quais geram bons resultados. Neste contexto, o problema estudado durante a pesquisa foi: Como as variáveis técnicas, econômicas, sociais e ambientais da propriedade analisada auxiliam na geração de renda e subsistência? O presente estudo teve por objetivo a análise e o diagnóstico dos aspectos econômicos, técnicos, sociais e ambientais de uma propriedade rural, que se dedica a produção de grãos localizada no município de Independência - RS, ano safra 2018/2019. Para auxiliar na obtenção e análise dos dados foram utilizados métodos de abordagem qualitativo e quantitativo, como métodos de procedimentos utilizou-se o estudo de caso e a pesquisa descritiva. Para a técnica de coleta de dados foi utilizada a observação direta e a entrevista não estruturada. Para análise dos dados coletados utilizou-se a análise de conteúdo e análise estatística para interpretar as questões econômicas da propriedade e das atividades. Como foi possível constatar, a principal atividade desenvolvida pela família

\footnotetext{
${ }^{1}$ Bacharel em Agronomia. ORCID: 0000-0002-6849-2174.

2 Bacharel em Agronomia. ORCID: 0000-0002-2493-0208.

${ }^{3}$ Bacharel em Agronomia. ORCID: 0000-0003-0064-1978.

${ }^{4}$ Orientador.
} 
é a produção de grãos, onde os membros da mesma trabalham na atividade, sendo que os filhos do casal pretendem dar continuidade às atividades que ali são desenvolvidas. No entanto, foi constatado alguns pontos a serem melhorados no sistema produtivo como: a introdução de um plano de rotação de culturas e terraceamento, bem como o uso de fertilizantes conforme a necessidade estabelecida na análise de solo, e alguns cuidados na proteção do meio ambiente. No que diz respeito a parte econômica da propriedade, a produção de grãos apresenta um bom rendimento a família, permitindo o investimento futuro na propriedade. Portanto, conclui-se, baseado em todo o estudo acima, que a propriedade estudada apresenta viabilidade, garantindo a sustentabilidade da mesma, com incentivo à sucessão familiar.

Palavras-chave: Unidade agrícola, Diagnóstico, Sistemas de Produção, Sucessão Familiar.

\section{INTRODUÇÃO}

O agronegócio vem se desenvolvendo cada vez mais, com a técnicas atualizadas e apropriadas consegue-se maximizar e facilitar o desenvolvimento de boas práticas agropecuárias, as quais levam a produção de bons resultados. Em consequência disso, há a geração de uma boa receita ao produtor, permitindo o crescimento da propriedade e estabilidade financeira, fatores estes, fundamentais para o sucesso em uma atividade.

Para tanto diversos estudos vêm sendo realizados na área, com o objetivo de planejar uma agricultura mais eficiente, diminuindo possíveis agressões aos meios de cultivo como degradação do solo e contaminação da água, através do consumo racional de insumos, evitando a utilização excessiva sem resultado efetivo, retomando, assim, algumas práticas de conservação de solo, assegurando que o bem mais valioso de um produtor seja tratado de forma mais correta, objetivando sempre o melhoramento das condições físicas e químicas do solo de sua propriedade. 
Para suprir e compor a modernização que vem ocorrendo nas últimas décadas, em várias áreas da agricultura, produz-se cada vez mais tecnologias em insumos e maquinário, que se tornam essenciais na realização das tarefas e que, consequentemente, afetam a produção e a rentabilidade.

Os estabelecimentos agrícolas têm sofrido várias mudanças, sendo que tem havido um decréscimo no tamanho na última década. $O$ trabalho desenvolvido nessas pequenas propriedades usualmente se dá por meio da mão de obra familiar, o que remete, muitas vezes, a serem exemplos de organização e gestão. Mediante a isto, muitas vezes, se tem alto investimento relacionado a tecnologia de ponta, fazendo com que o trabalho no campo seja de maior facilidade e rentabilidade, proporcionando uma maior fixação de pessoas no campo.

Conforme Fernandes e Salamoni (2012), o diagnóstico dos sistemas agrários proporciona um melhor entendimento de todo o contexto que a propriedade está inserida considerando os aspectos ambiental, social e econômico, bem como identificando as suas principais características. De forma prática, o diagnóstico permite compreender quatro pontos principais que são: 1) o levantamento das características sociais, econômicas e ambientais da propriedade em questão; 2) identificar os sistemas de produção e os seus manejos adotados pelos proprietários e seus principais problemas; 3 ) identificar os principais elementos relacionados às questões ecológicas, social, técnica, cultural, econômica e política que representam a realidade que está sendo estudada; e 4) sugerir proposições de melhorias nos pontos levantados no estudo que estão em situação crítica e gerando pouco retorno ao produtor.

Assim, o diagnóstico dos aspectos sociais, ambientais, técnicos e econômicos que envolvem todas as atividades e a propriedade como um todo se faz necessário, pois é através desse levantamento que o proprietário terá uma visão mais ampla dos pontos que necessitam de melhorias e quais podem continuar. E, dessa maneira, promover o aumento da rentabilidade da propriedade, por meio do uso de atividades e/ou culturas alternativas, conservação dos recursos naturais, uso de agroquímicos conforme a necessidade das culturas e do solo, além de promover a conservação dos 
recursos hídricos disponíveis, refletindo na melhoria da qualidade de vida do proprietário e da sua família, que residem neste local e tiram o seu sustento da mesma, incentivando que as futuras gerações continuem na atividade.

Para tanto, o estudo em questão visou apontar melhorias necessárias não somente para a produção como também para o sistema organizacional de uma propriedade rural de 200 hectares no município de Independência, situada na região Noroeste do Estado do Rio Grande do Sul, observando os aspectos sociais, econômicos, técnicos e ambientais, visando encontrar alternativas que melhorem os resultados, e garantam uma maior qualidade de vida e a constante preservação do meio ambiente.

Neste contexto, o problema estudado durante a pesquisa foi: Como as variáveis técnicas, econômicas, sociais e ambientais da propriedade analisada auxiliam na geração de renda e subsistência? O presente estudo teve por objetivo a análise e o diagnóstico dos aspectos econômicos, técnicos, sociais e ambientais de uma propriedade rural, que se dedica a produção de grãos localizada no município de Independência - RS, ano safra 2018/2019.

\section{ASPECTOS METODOLÓGICOS}

O presente estudo visa diagnosticar as diversas variáveis envolvidas no processo produtivo primário de uma propriedade rural localizada no município de Independência - RS, considerando os aspectos técnicos, sociais, econômicos e ambientais, no primeiro semestre de 2019.

O problema estudado durante a pesquisa foi: Como as variáveis técnicas, econômicas, sociais e ambientais da propriedade analisada auxiliam na geração de renda e subsistência?

Em busca de solucionar tal problema, apontou-se as seguintes hipóteses: A declividade das glebas está relacionada com o cultivo instalado. Os indicadores apresentam níveis de alta fertilidade para as respectivas glebas. Os indicadores físicos de densidade do solo, resistência à penetração e infiltração, estão em níveis adequados para culturas praticadas. As glebas de cultivo da propriedade em estudo 
apresentam práticas conservacionistas que permitem um controle eficiente de erosões. Os índices de $\mathrm{P}$ e $\mathrm{K}$ se apresentaram em níveis altos, proporcionando um bom desenvolvimento das culturas praticadas. As atividades desenvolvidas na propriedade, na sua diversidade de cultivo geram resultados positivos em termos de lucratividade. O produtor e sua família possuem interação ativa e harmônica com a comunidade onde residem. Na propriedade em estudo há perspectiva de sucessão familiar.

Foi utilizado o método de abordagem quantitativo para as questões relacionadas a parte econômica da propriedade, como: benfeitorias, receitas, custo de produção, viabilidade de cada atividade, levantamento planialtimétrico do local, penetrometria do solo. Já, o método qualitativo, foi utilizado para avaliar a relação social da família com: o meio externo, a comunidade em que estão inseridos, sua convivência com cooperativas e o meio rural, todos os maquinários, imóveis, equipamentos existentes, e os aspectos ambientais que regem a mesma, além da perspectiva futura para a propriedade, principalmente visando a sucessão familiar.

Os métodos de procedimento utilizados foram: o método de estudo de caso, para coletar o histórico da propriedade, sendo as receitas e, a pesquisa descritiva, para descrever todas as informações coletadas sobre a propriedade em estudo para a realização do diagnóstico.

Como técnicas de coleta de dados utilizou-se a técnica de observação direta intensiva para analisar os aspectos que norteiam os fatores sociais, ambientais, técnicos e econômicos analisados. E, a técnica de entrevista, foi aplicada neste estudo de forma não padronizada e não dirigida, no intuito de proporcionar ao entrevistador liberdade na condução da pesquisa, direcionando-a conforme julgar adequado. A técnica da entrevista foi aplicada no estudo para levantar dados relevantes sobre a propriedade rural juntamente com o proprietário e administrador das atividades nela realizadas.

A técnica de análise de conteúdo foi aplicada, ainda, para avaliar os processos envolvidos no sistema produtivo da propriedade e, também, para analisar a bibliografia 
consultada durante o desenvolvimento deste artigo. Além disso, foi usada a estatística com o emprego de cálculos para a avaliação econômica da propriedade.

\section{REFERENCIAL TEÓRICO}

As propriedades rurais são partes da sociedade em que estão inseridas, por isso, têm como responsabilidade atender as obrigações sociais e trabalhistas e observar o impacto que produzem sobre o bem-estar humano, o meio ambiente e a sociedade. Dessa forma, irão gerar recursos financeiros, serão provedoras de benefícios ao seu meio e atenderão demandas de mercados que buscam um produto final com qualidade e segurança, resultante de cadeias produtivas competitivas, ambientalmente corretas e socialmente justas (VALLE, 2007).

Segundo Tesche (2007), as relações sociais no meio rural podem ser classificadas em duas: externas e internas. As externas são a participação e o envolvimento em cooperativas e associações e, as internas, pelo relacionamento entre as pessoas do círculo de família.

A agricultura familiar consiste na utilização da mão de obra da própria família que é responsável pela geração de renda, sendo a mesma, gestora da propriedade, não possuindo área maior que 4 módulos fiscais, sem utilização de mão de obra assalariada de terceiros, sendo responsável pela grande parte dos alimentos produzidos, principalmente, pelo fato de produzir e consumir, tendo uma renda mínima através das atividades desenvolvidas na propriedade (ANDRIOLI et al., 2009).

Segundo Brandão (2015), a sucessão familiar ainda necessita de grandes observações a serem realizadas, principalmente pela sequência de uma atividade que muitas vezes acaba não sendo de interesse, além é claro de muitas vezes serem empresas conservadoras, sem tecnologia e ultrapassadas, se tornando incapazes de se atualizar. Sendo assim, sofrem o risco de ter seu crescimento comprometido. Portanto, há a necessidade de investimento e demonstração de que é possível melhorar sempre em todas as atividades, pois mesmo na agricultura, há cada vez 
mais um cenário globalizado e competitivo, perdendo espaço para baixos rendimentos e pouco emprego de tecnologia.

O manejo da fertilidade do solo depende da correta amostragem e de um laboratório credenciado para realização de análise química e física. O diagnóstico dos resultados obtidos pela análise de solo possibilitará a execução de um planejamento da adubação, levando em conta a espécie que será cultivada. Para a medição da fertilidade de um solo, a análise realizada pelo laboratório deve conter os resultados de teor de argila, $\mathrm{pH}$ em água, quantidade de nutrientes disponíveis, elementos indesejáveis tóxicos às plantas, realizando, assim, as recomendações de correção (TROEH; THOMPSON, 2007).

A cultura do milho para o Rio Grande do Sul apresenta significativa importância socioeconômica, ocupando aproximadamente $15 \%$ do total das áreas semeadas com cultivos de primavera-verão, somando as áreas destinadas para a produção de grãos e para silagem. Essa importância socioeconômica se evidencia na cultura do milho, porque este é matéria-prima fundamental para as cadeias produtivas de aves, suínos e leite (62 REUNIÃO DE PESQUISA DE MILHO E SORGO DA REGIÃO SUL, 2017).

Em relação a cultura da soja, o Brasil, destaca-se como o segundo maior produtor mundial, ficando atrás dos Estados Unidos. A produção brasileira de soja correspondeu em 2015/2016 a 30\% da produção mundial, sendo o Mato Grosso o maior Estado produtor do grão no Brasil, com 26,058 milhões de toneladas, seguido pelos Estados do Paraná com 17,102 milhões de toneladas e do Rio Grande do Sul com 16,201 milhões de toneladas (GARCIA, 2017).

Já a produção nacional de trigo, está concentrada na região Sul do Brasil e corresponde a $90 \%$ da produção nacional. $O$ rendimento deste cereal aumentou expressivamente nos últimos 50 anos, como consequência dos esforços dos programas de melhoramento genético. Na década 1960, a produção era de $771 \mathrm{~kg}$ ha${ }^{1}$ ano, enquanto em 2015, a produção anual foi de $2.382 \mathrm{~kg} \mathrm{ha}^{-1}$. (BONA; MORI; WIETHÖLTER, 2016). 
Dentro de uma propriedade rural, além das atividades desenvolvidas com fins comerciais, também, há as atividades de subsistência, as quais caracterizam-se pela baixa produção e a utilização de recursos pouco tecnológicos. Dentre as atividades de subsistência, se destacam a produção de feijão, mandioca, hortaliças, piscicultura, apicultura, criação de bovinos de corte, suínos, aves e pomar para produção de frutas (SANTIAGO, 2011).

Diante os fatos expostos, ainda ressalta-se a legislação ambiental em uma propriedade rural é de extrema importância, visto que todas as atividades realizadas colaboram de forma direta e também indireta na sustentabilidade da unidade agrícola (KLEIN; ROSA, 2011).

Por fim, para avaliar economicamente uma propriedade rural, é necessário levantar todos os dados financeiros possíveis onde, para Silva (2005, p. 6), "o demonstrativo relata a história da atividade durante um exercício social ou durante períodos mais curtos, que podem ser, por exemplo, um trimestre ou um semestre".

\section{APRESENTAÇÃO DOS RESULTADOS}

A história da unidade produtiva pesquisada teve início quando Jorge Meller e Conceição Meller se casaram em 20 de maio de 1946 e foram residir na localidade de Esquina Neves, no interior do município de Catuípe, cerca de $10 \mathrm{~km}$ distante de onde se localiza a sede atual.

Atualmente, as decisões tomadas na propriedade são feitas pelos seus filhos. A propriedade conta com 3 áreas próprias e 3 áreas arrendadas, focadas na produção de grãos de soja, milho e trigo, além de ovinos, que são o hobby da família, e demais culturas destinadas para subsistência.

Os proprietários participam da relação social entre a família, onde o trabalho é somente familiar. Além de ter o senhor Darci para gerir a propriedade, as decisões são tomadas em conjunto, uma vez que todos estão envolvidos no processo de produção, tendo uma boa relação de convivência entre os irmãos e seus cônjuges. 
Sempre que possível, eles participam de dias de campo, palestras ou cursos relacionados as atividades desenvolvidas para aperfeiçoar conhecimentos e buscar novas tecnologias. Onde, segundo Carmo e Colognese (2010), a participação nesses eventos promovidos por entidades e instituições ligadas ao meio rural auxiliam os produtores na melhoria das atividades que são desenvolvidas, bem como demonstrar novas técnicas de cultivo existentes e mais eficazes, que irão refletir no aumento da produtividade das atividades que ali estão sendo apresentadas.

Os proprietários da propriedade em estudo pensam em uma possível sucessão das atividades ao filho Jair, de Maria uma das proprietárias, o qual tem 47 anos, possui curso de gestão da qualidade, tem experiência com mecânica pesada, faz as manutenções do maquinário da propriedade e participa dos processos produtivos, ajudando efetivamente no trabalho da propriedade, mostrando-se interessado em suceder as atividades.

Além disso, o filho de Abílio, no momento, não está ajudando no processo produtivo da propriedade. No entanto, está cursando a graduação em agronomia para, futuramente, através do conhecimento obtido, contribuir ainda mais na qualidade dos processos que envolvem a produção da propriedade.

Estes, então, irão trabalhar em conjunto para a evolução dos processos da propriedade, sendo que todos os envolvidos estão cientes do mesmo, e chegaram a um acordo de como esse processo deverá ocorrer.

A propriedade é composta por 6 glebas, sendo que 3 delas são próprias, as quais se delimitam por Gleba Sede, Tapera e Air. Já as glebas Pedro, Luiza e Lanzanova são arrendadas.

A sede da propriedade fica situada na comunidade de Colônia Glória, município de Independência, $3 \mathrm{Km}$ distante da comunidade de Esquina Araújo. A gleba da sede conta com uma área total de 64,5 hectares, sendo que 1 hectare é ocupado pelas instalações da propriedade, contendo galpões, casas, área de cultivos de subsistência e criação de animais, como pode se visualizar na figura 01. 
Figura 01 - Sede da Propriedade

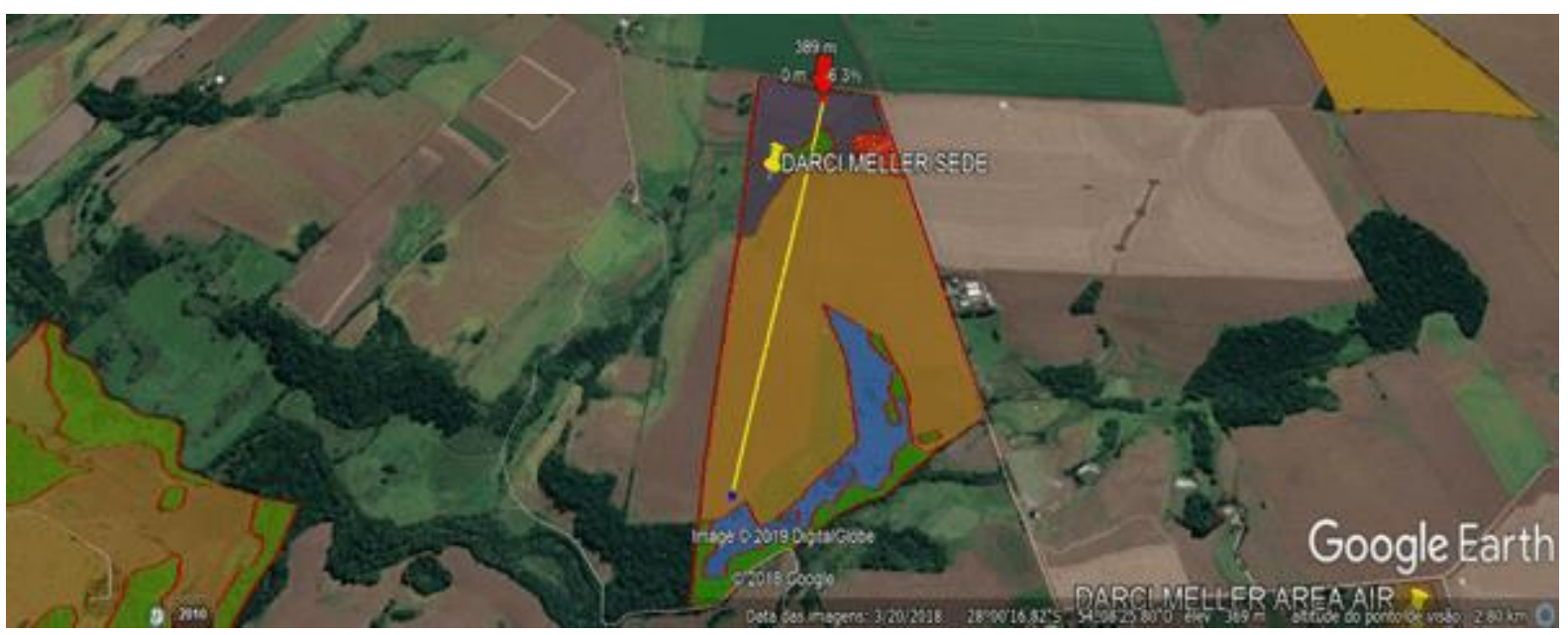

Fonte: Google Earth

Nesta gleba é feita a criação de animais para a subsistência, para isso há a pastagem de grama nativa, ocupando uma área de 9,8 hectares que são destinados para a alimentação dos bovinos, se localizando aos fundos da área da propriedade. Ao lado da sede, se tem áreas de pastagem com grama estolonífera, a qual serve de uso para o pastejo das ovelhas. Na área da sede é realizado cultivo de trigo no inverno, nesta área foram cultivados 8 hectares com milho no verão, e o restante dos 50 hectares com soja. Existem terraços na área, a semeadura é feita em nével e somente sucessão de culturas.

A gleba Lanzanova compreende uma área total de 24,7 hectares, sendo que sua área de cultivo é de 20,5 hectares. Esta área fica situada a cerca de 1,5 km da área da sede, é arrendada pela família desde 2016. Na figura 02 observa-se gleba Lanzanova. 
Figura 02 - Gleba Lanzanova

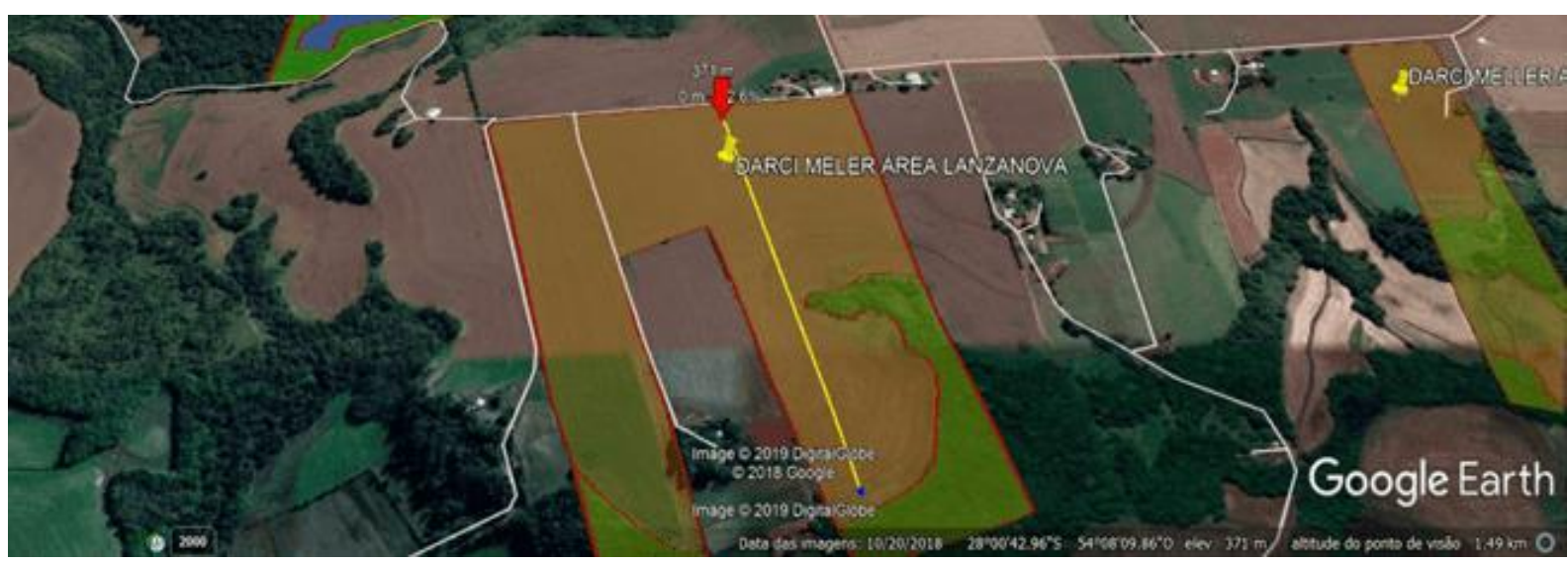

Fonte: Google Earth

Nesta gleba, utiliza-se a sucessão das culturas de soja e trigo, pois chegou-se à conclusão de que não era viável a utilização de rotação de culturas e, por serem algumas das principais commodities de grãos, tem venda facilitada. Não existe a utilização de terraços na área, além disso, utiliza-se a semeadura de acordo com o terreno. A mata nativa não é utilizada pelos arrendatários. Nesta gleba, a quantidade de mata corresponde a cerca de $17 \%$ da área total.

O valor pago pelo arrendamento desta área corresponde a 17 sacas de soja por hectare de cultivo, perfazendo uma quantia de 340 sacas de soja. A declividade média desta área é de $5,2 \%$, sendo considerada uma área com pouca declividade e de fácil cultivo, no que diz respeito à mecanização agrícola.

$\mathrm{Na}$ safra de trigo 2018, obteve-se um rendimento de 45 sacas de trigo $\mathrm{pH} 78$ por hectare, totalizando 922 sacos de trigo na área total. Na safra de verão 2018/2019, foi cultivada soja nesta gleba, obtendo-se uma produtividade média de 58 sacas de soja por hectare, totalizando uma produção de 1.189 sacas de soja nesta área.

A gleba denominada Luiza se localiza no município de Giruá e se localiza a $8 \mathrm{~km}$ da área da sede, compreende uma área total de 75,5 hectares, sendo 55 hectares de cultivo, no qual se efetua a semeadura de acordo com o terreno. Esta diferença na área de cultivo demonstra que $27 \%$ da gleba não é cultivada, pois existe a mata. 
Figura 03 - Gleba Luiza

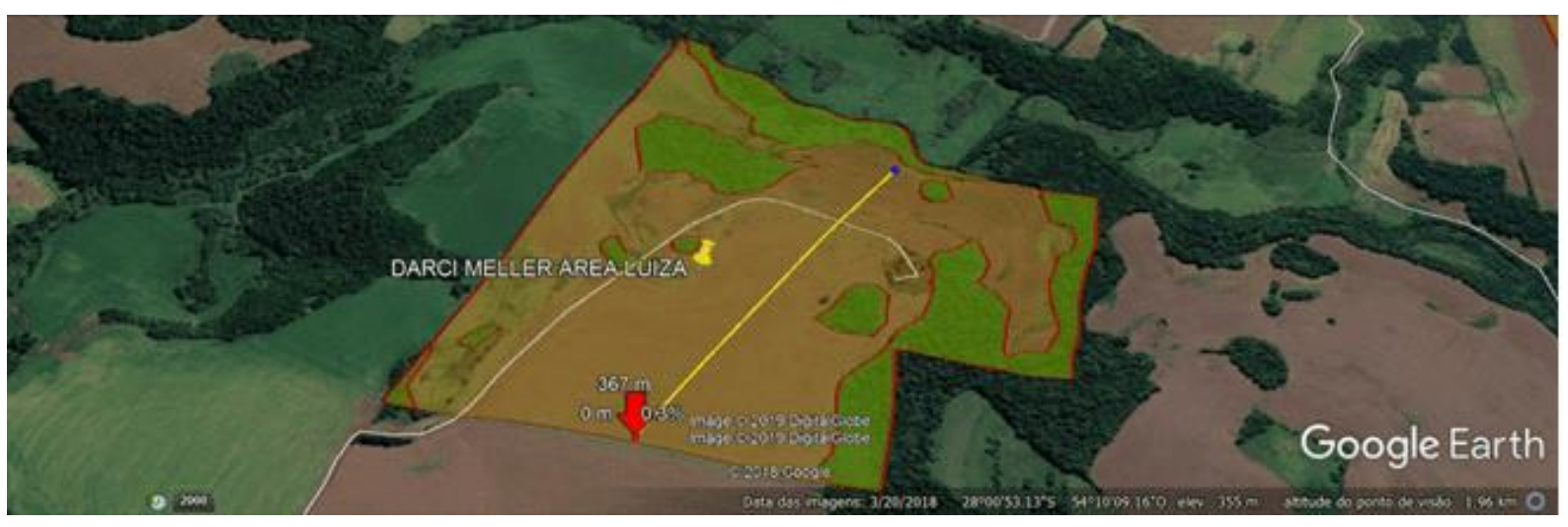

Fonte: Google Earth

Nesta área, o produtor utiliza a sucessão de culturas com soja e trigo, esta é arrendada desde o ano de 2009, na qual, por questão de decisão dos donos, o produtor irá entregar a área após o cultivo de trigo safra 2019. Nesta área não existem terraços, somente é utilizada a semeadura conforme os níveis do terreno, sendo prejudicial para área.

Como forma de arrendamento, o Sr. Darci, paga 15 sacas de soja por hectare de cultivo desta área, perfazendo uma quantidade total de 750 sacas de soja a cada ano. A declividade desta área varia de $1,4 \%$ até $20 \%$, porém a média fica em torno de $7,1 \%$, o que não dificulta a atividade das máquinas agrícolas.

Nesta área foi cultivado trigo na safra 2018, obtendo uma produtividade de 32 sacas de trigo $\mathrm{Ph} 78$ por hectare, resultando em uma produção total de 1760 sacos de trigo. Na safra de verão 2018/2019, foi cultivado soja e obtido uma produtividade de 48 sacas por hectare, perfazendo uma produção total de 2640 sacas de soja.

A gleba denominada Tapera está situada a 2 quilômetros da sede da propriedade, esta compreende 27 hectares de área total e o cultivo é para a própria família. Apresenta declividade que varia de 1 até $16 \%$, com média em torno de $6 \%$, porém isto não dificulta em nada o desempenho das máquinas agrícolas. 
Esta área é definida pelo Sr. Darci com a melhor gleba da propriedade no que se refere a facilidade no desempenho das máquinas agrícolas. Ela pode ser visualizada na figura 04

Figura 04 - Gleba Tapera

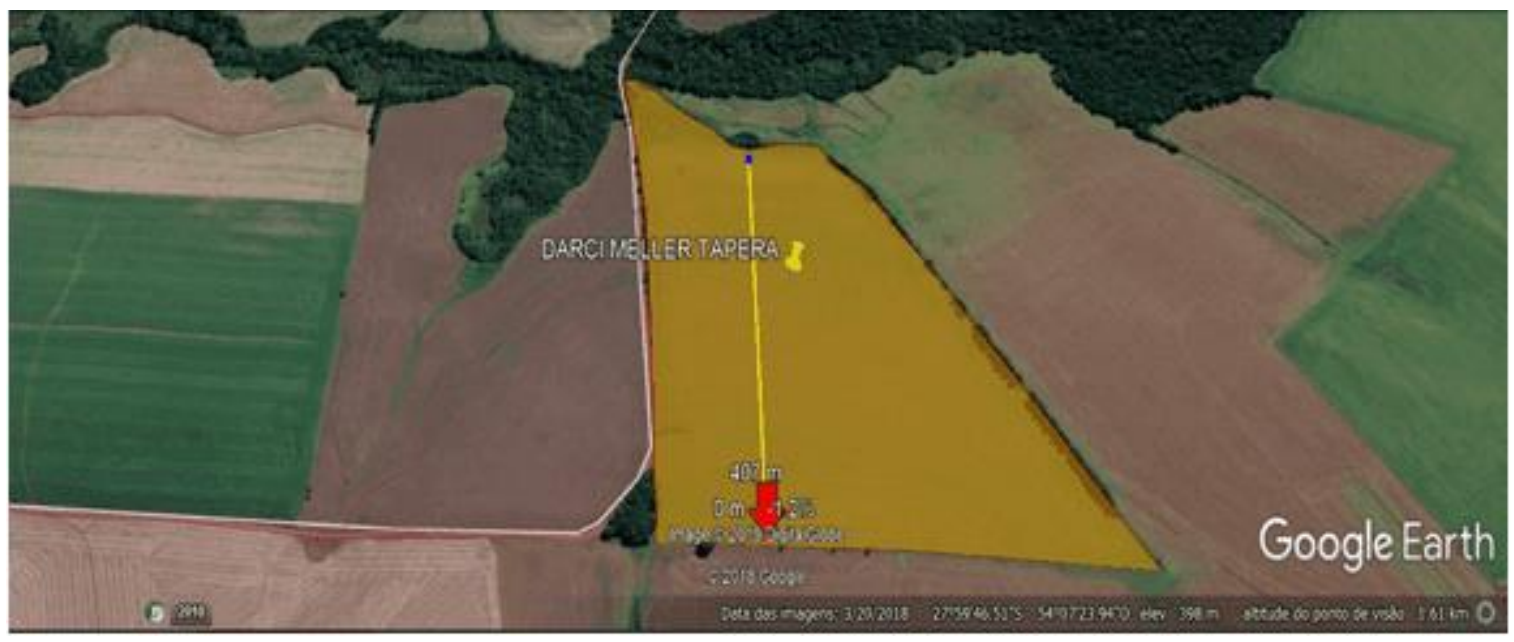

Fonte: Google Earth

Em relação aos cultivos realizados nessa área, na safra de inverno 2018 , foi cultivado trigo, obtendo uma produtividade de 40 sacas por hectare, somando um total de 1080 sacas de trigo com pH 78. Na safra de verão 2018/2019, foi cultivado soja nesta área, com um rendimento de 54 sacos de soja por hectare, sendo o total de 1458 sacos de soja. Existe terraceamento da área, no qual é necessário que sejam feitas manutenções, pois se houver um volume de chuvas elevado, pode ocorrer erosões no solo, portanto, utiliza-se a semeadura em nível.

A gleba denominada Air está localizada a 2,1 quilômetros da área da sede. Esta foi adquirida no ano de 2018 e possui uma área total de 7 hectares, sendo 2,1 a área de cultivo, possuindo $30 \%$ de mata nativa. 
Figura 05 - Gleba Air

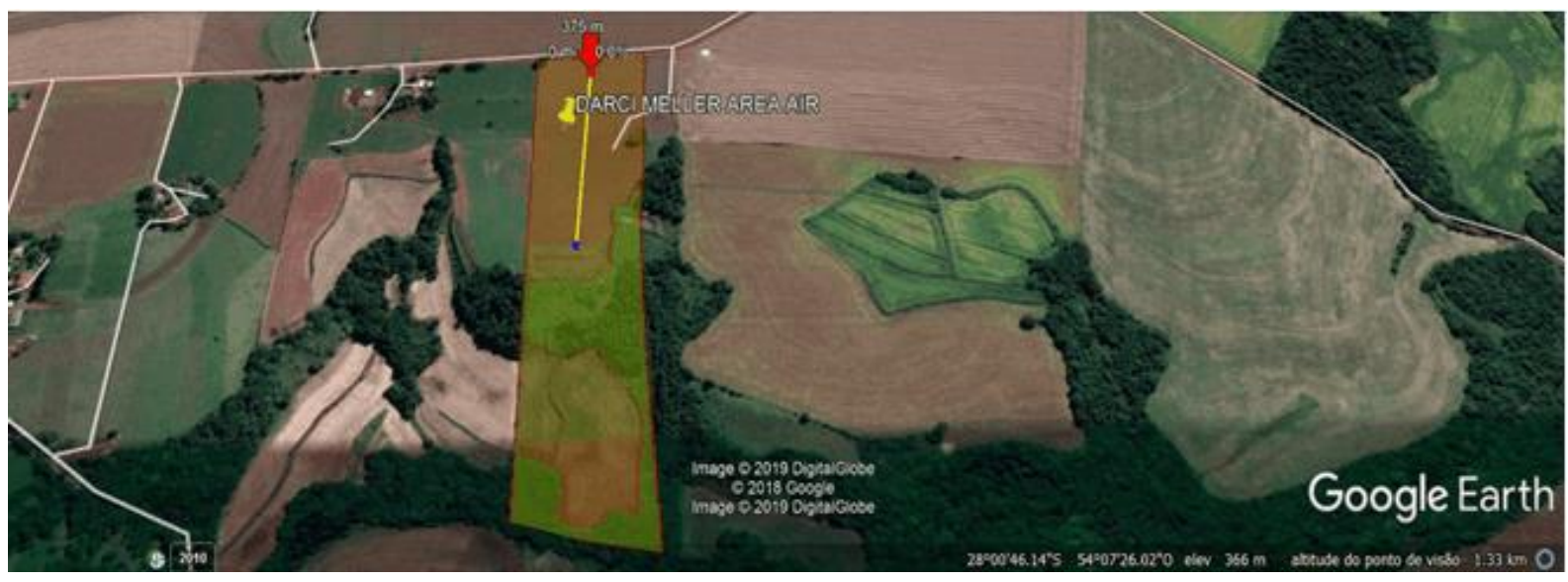

Fonte: Google Earth

Esta área apresenta declividade que varia de 2,0 até 8,8\%, sendo a média de 7,2\%. Em relação aos cultivos, na safra de inverno de 2018 ficou em pousio, pois como esta área foi adquirida a pouco tempo os proprietários decidiram deixar em pousio para realizar algumas melhorias. Não existem terraços na área, o produtor faz a semeadura em nível e utiliza o sistema de semeadura direta. Na safra de verão, foi cultivado soja, obtendo uma produtividade de 43 sacas por hectare. Seu Darci relatou que essa baixa produtividade pode estar atribuída à baixa fertilidade desta área, pois os antigos donos não faziam adubação conforme necessário.

A área Pedro está localizada a 10 quilômetros da sede. É uma área alugada, na qual são 15,5 hectares de cultivo, que o produtor aluga por 230 sacas de soja, sendo 15 sacas por hectare de cultivo. Não há presença de terraços na área, somente é praticada a semeadura em nível no sistema de semeadura direta, sendo visualizada na figura 06. 
Figura 06 - Gleba Pedro

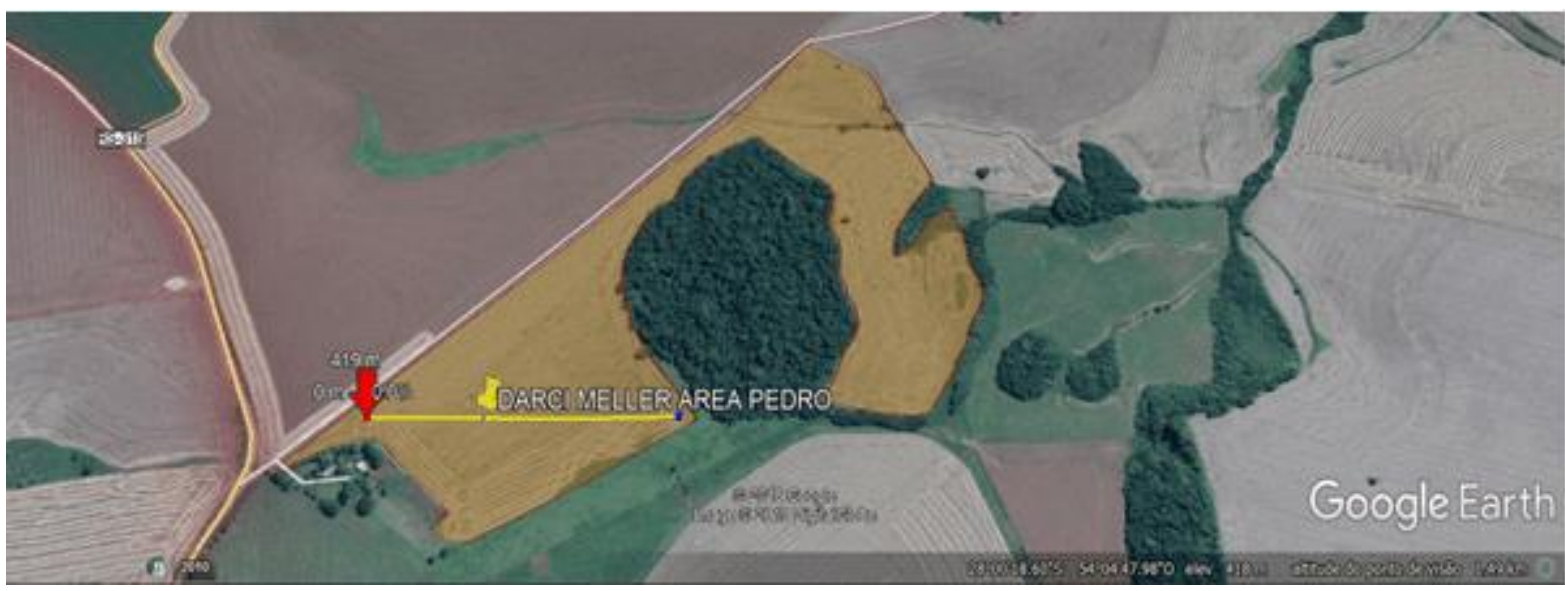

Fonte: Google Earth

Esta área apresenta uma declividade média de 5,4\%, sendo considerada uma área de fácil manejo. Nela é realizada a sucessão de culturas com trigo e soja. No inverno de 2018 , foi cultivado trigo e, no cultivo de verão 2018/2019, foi cultivado soja.

Como se verifica, as glebas da propriedade não possuem um sistema de conservação do solo, o que impossibilita melhoria nas condições físicas, químicas e biológicas, bem como na infiltração de água no solo. Assim, o terraceamento é uma prática conservacionista que, segundo Cunha et al. (2011), permite maior infiltração de água no solo e disciplina o escoamento destas até um córrego de drenagem. Entretanto, este deve ser associado a outros métodos, como a rotação de culturas, para que ocorra maior aporte de palhada no solo, o que contribuirá para elevar os teores de matéria orgânica e porosidade do solo. Desta maneira, os proprietários devem passar a fazer usos dessas técnicas para que ocorra melhoria na qualidade do solo e, consequentemente, na produtividade das culturas.

No quadro 01 apresenta-se as interpretações dos resultados das análises de solo de forma geral. 
Quadro 15 - Interpretação das análises de solo

\begin{tabular}{|c|c|c|c|c|c|c|c|c|c|}
\hline $\begin{array}{l}\text { Prof. } \\
\text { Col. }\end{array}$ & Amostra & Gleba & $\begin{array}{l}\text { Área } \\
\text { (Ha) }\end{array}$ & M. 0. & $\mathbf{P}$ & $\mathrm{K}$ & $\mathrm{Ca}$ & Mg & $\begin{array}{l}\mathrm{pH} \\
\mathrm{H} 2 \mathrm{O}\end{array}$ \\
\hline $\begin{array}{l}0-10 \\
\mathrm{~cm}\end{array}$ & 44217 & Sede & 50 & Alto & $\begin{array}{l}\text { M. } \\
\text { Alto }\end{array}$ & Alto & Alto & Alto & 6 \\
\hline $\begin{array}{l}10-20 \\
\mathrm{~cm}\end{array}$ & 44218 & Sede & 50 & Médio & Baixo & Baixo & Alto & Alto & 5,7 \\
\hline $\begin{array}{l}0-10 \\
\mathrm{~cm}\end{array}$ & 44208 & Lanzanova & 20,5 & Alto & $\begin{array}{l}\text { M. } \\
\text { Alto }\end{array}$ & Alto & Alto & Alto & 5,4 \\
\hline $\begin{array}{l}10-20 \\
\mathrm{~cm}\end{array}$ & 44209 & Lanzanova & 20,5 & Médio & Médio & Baixo & Alto & Alto & 5,6 \\
\hline $\begin{array}{l}0-10 \\
\mathrm{~cm}\end{array}$ & 44205 & Luiza & 55 & Alto & Médio & Alto & Alto & Alto & 5,4 \\
\hline $\begin{array}{l}10-20 \\
\mathrm{~cm}\end{array}$ & 44206 & Luiza & 55 & Médio & Baixo & Baixo & Alto & Alto & 5,7 \\
\hline $\begin{array}{l}0-10 \\
\mathrm{~cm}\end{array}$ & 44211 & Tapera & 27 & Alto & $\begin{array}{l}\text { M. } \\
\text { Alto }\end{array}$ & Médio & Alto & Alto & 5,9 \\
\hline $\begin{array}{l}10-20 \\
\mathrm{~cm}\end{array}$ & 44212 & Tapera & 27 & Alto & Alto & Médio & Alto & Alto & 5,9 \\
\hline $\begin{array}{l}0-10 \\
\mathrm{~cm}\end{array}$ & 44214 & Air & 7 & Alto & $\begin{array}{l}\text { M. } \\
\text { Alto }\end{array}$ & $\begin{array}{l}\text { M. } \\
\text { Alto }\end{array}$ & Alto & Alto & 6,4 \\
\hline $\begin{array}{l}10-20 \\
\mathrm{~cm}\end{array}$ & 44215 & Air & 7 & Médio & Baixo & $\begin{array}{l}\text { M. } \\
\text { Alto }\end{array}$ & Alto & Alto & 6,2 \\
\hline $\begin{array}{l}0-10 \\
\mathrm{~cm}\end{array}$ & 44202 & Pedro & 15,5 & Alto & Alto & Baixo & Alto & Alto & 5,3 \\
\hline $\begin{array}{l}10-20 \\
\mathrm{~cm}\end{array}$ & 44203 & Pedro & 15,5 & Médio & Alto & Baixo & Alto & Alto & 5,1 \\
\hline $\begin{array}{l}0-10 \\
\mathrm{~cm}\end{array}$ & 44199 & Pastagem & 9,8 & Alto & Baixo & Médio & Alto & Alto & 5,6 \\
\hline
\end{tabular}




\begin{tabular}{|l|l|l|l|l|l|l|l|l|l|}
\hline $\begin{array}{l}10-20 \\
\mathrm{~cm}\end{array}$ & 44200 & Pastagem & 9,8 & Médio & $\begin{array}{l}\text { M. } \\
\text { Baixo }\end{array}$ & Baixo & Alto & Alto & 5,8 \\
\hline
\end{tabular}

Fonte: Kreutz; Jeziorski; Silva; Meller (2019)

Comparando o teor de argila presente no solo, as glebas se encaixam na classe textural 1, apresentando um teor de argila superior a $60 \%$. No procedimento de recomendação de calagem, deve-se levar em consideração alguns critérios que avaliam o pH do solo e a saturação da CTC por alumínio. Entre as glebas analisadas, a pastagem apresentou o índice de $\mathrm{pH}$ muito alto e, nas glebas Lanzanova, o teor do pH está em nível baixo.

Para fazer a recomendação da calagem, analisa-se o pH e o percentual de saturação de bases. A quantidade de corretivo a ser aplicada depende do $\mathrm{pH}$ em água. $\mathrm{A}$ quantidade aplicada resultará em uma diminuição da acidez potencial do solo, que é expressa pelo índice SMP. À medida que o SMP aumenta, a acidez do solo diminui. Para estimar quanto de calcário será utilizado, é importante observar o percentual PRNT (Poder Relativo de Neutralização Total), para que a quantidade deste tamponante seja a correta.

A capacidade de troca de cátions e os teores considerados médios, que ficam entre $(7,6$ - 15,0), se enquadram nas glebas estudadas. Ao analisar a saturação por alumínio, observa-se que Lanzanova 2 apresenta baixo teor, ficando entre (1 - 10\%). Analisando a saturação por bases, as duas glebas Lanzanova se enquadram no teor baixo (45\% - 64\%) e a gleba Pastagem apresenta o teor alto $(75 \%-80 \%)$.

Os níveis de pH da gleba Pedro nas duas profundidades coletadas, 0-10 e 10-20 cm, são considerados como ácidos, pois estes apresentam-se um nível alto de Alumínio, 0,8 e 2,5 respectivamente, além da saturação de bases ser de 43,8 e 28,1, indicando que será necessária a calagem para correção do nível de acidez do solo.

A matéria orgânica é essencial para calcular a quantidade de nitrogênio na adubação e, ainda, ajuda a manter a estrutura, fornecendo, assim, um aporte de $\mathrm{N}$ maior para as culturas sucessoras. Verificou-se que as glebas estudadas apresentaram teor de 
M.O entre médio a alto, onde a gleba Air apresentou o menor dos valores encontrados 2,5\% de M.O e, as glebas Sede e Luiza, apresentaram os maiores teores de matéria orgânica, o qual foi de 3,6\% na profundidade de $0-10 \mathrm{~cm}$ para ambas.

No momento de interpretar os teores de fósforo é necessário conhecer os teores de argila e o teor do P. Considerando as glebas estudadas, obteve-se os níveis médios $(6,1-9,0)$ para a Lanzanova 1 e Pastagem, e nível alto $(9,1-12,0)$ na Lanzanova 2. Para tanto, o potássio, é interpretado através dos teores da CTC ao mesmo tempo que também é preciso saber o teor de $\mathrm{K}$ contido no solo. Os resultados obtidos através da análise de solo indicam um nível muito alto para as glebas Lanzanova e teor médio para a gleba Pastagem.

Segundo Broch e Ranno (2012), a interpretação dos teores necessários de calagem e adubação são práticas de grande importância na contribuição do aumento da produtividade das culturas. Assim, a recomendação de adubação e calagem para a análise de solo ocorre por meio da interpretação dos níveis de nutrientes presentes nele, determinando, dessa maneira, a quantidade de corretivo e fertilizantes necessários para se alcançar a produtividade desejada a cultura a ser implantada.

De acordo com o relato dos proprietários, são poucos os produtos adquiridos para a alimentação dos moradores, devido a produção de alimentos ocorrer dentro da propriedade, onde são cultivadas espécies olerícolas, mandioca, frutas e carne. Toda essa produção corresponde ao valor de $R \$ 13.441,50$ que deixam de ser gastos com a compra de alimentos.

Os maiores valores para compra de produtos hortícolas, caso houvesse compra destes, em relação aos produtos hortícolas a mandioca, corresponde a $R \$ 440,00$ e o tomate $R \$ 210,00$, já para as frutas, a pitanga com $R \$ 375,00$ e a noz pecan com $R \$$ 375,00 . Os derivados de animais possuem o maior valor agregado, em comparação aos demais produtos produzidos na propriedade, onde a carne bovina corresponde ao maior custo anual com $R \$ 4.140,00$, além da carne ovina com $R \$ 3.480,00$. 
Verificou-se a grande diversidade de cultivos existente na propriedade, sempre realizando colheitas fartas dos cultivos, prezando a qualidade, já que é oferecida para os membros da família e não comercializado.

A atividade de subsistência, conforme destaca Grisa e Schneider (2014), proporciona maior segurança alimentar e economia de recursos. Assim, muitas propriedades rurais desenvolvem essa atividade, o que representa uma autonomia dos proprietários para produzir produtos com maior qualidade e com recursos pouco desenvolvidos.

Esta propriedade, em questão, contempla uma conservação de solo, com terraceamento em nível em duas glebas, a qual tem a finalidade de impedir com que a água escorra com maior velocidade sobre o solo, causando erosões. Porém, é visível os danos causados pelas excessivas chuvas, onde existem escorrimentos superficiais nas demais glebas, demonstrando a necessidade da implantação de mais terraços na propriedade.

Nas glebas que contém as curvas de níveis é possível visualizar erosões superficiais, pelo fato destas não possuírem a devida manutenção prevista pelas práticas conservacionistas e por estarem em um cultivo de sucessão de culturas Trigo/Soja, onde não se tem a rotação apropriada e quantidade de palhada necessária para a cobertura eficiente do solo.

Já sobre o abastecimento de combustível do maquinário da propriedade, é realizado ao lado do galpão em um tanque de metal. Os óleos utilizados para lubrificar alguns equipamentos, motosserras e correntes das semeadoras, são dispostos em um tonel para evitar que poluam o solo. Em relação aos filtros, o produtor faz somente a decantação do óleo e os armazena em uma caixa, para que quando seja realizada a coleta seletiva pela prefeitura municipal, esse material seja entregue.

Quanto às áreas de preservação permanente, na área da Sede não são consolidadas, pois não se tem delimitações que impeçam a entrada dos animais, que são utilizados para a subsistência, na propriedade. Além dessa, as outras glebas, têm áreas de vegetação nativa na qual o produtor não utiliza a nenhum fim. 
Em relação aos dejetos dos animais, estes são coletados e espalhados na área da horta, como fonte de adubo orgânico. E, em relação à água utilizada para as pulverizações e para o abastecimento do pulverizador, o produtor utiliza água proveniente de uma fonte da sede propriedade, bombeando-a desta fonte. Para as aplicações nas áreas distantes da sede, se utiliza um tanque de $4.000 \mathrm{~L}$, o qual é transportado no caminhão e é utilizado para armazenar a água necessária para as pulverizações.

A propriedade não conta com um espaço específico para o armazenamento dos agrotóxicos e das embalagens vazias. Estes são armazenados em um canto do galpão, sem ser feita separação por finalidade dos produtos ou separação das embalagens já utilizadas e que devem ser devolvidas. Dessa forma, aumenta-se as chances de ocorrer contaminação cruzada entre os produtos.

No entanto, Souza e Palladini (2005), destcam que os produtores devem ter o cuidado no armazenamento das embalagens de agrotóxicos sejam estas cheias ou vazias, de forma que não ocorra a contaminação do solo. E elas devem ser destinadas de maneira adequada após o seu uso, efetuando a tríplice lavagem, tendo a parte inferior perfurada e armazenagem realizada adequadamente.

As áreas próprias da propriedade estão cadastradas no CAR (Cadastro Ambiental Rural) e estão de acordo com a lei, pois se tratam de áreas menores que 4 módulos fiscais, de acordo com cada sucessor delas. De acordo com a Lei no 12.651 (BRASIL, 2012), a inscrição no CAR é o primeiro passo para se obter a regularidade ambiental do imóvel, onde deve contemplar os dados do proprietário, dados de comprovação da propriedade, informações do tamanho da área, remanescentes de vegetação nativa, áreas de preservação permanente, áreas consolidadas e reserva legal. Com esse documento, o produtor tem acesso às políticas públicas disponíveis, bem como regulariza a falta de área de preservação permanente da propriedade.

Desde o princípio, a produção agrícola, deveria andar lado a lado com o meio ambiente, cultivando sem agredi-lo, cuidando dos seus recursos e preservando-os. $\mathrm{O}$ 
solo que cultivamos é o maior bem do produtor rural, que inúmeras vezes acaba sendo deixado de lado para facilitar o seu cultivo.

O balanço patrimonial da propriedade foi realizado com o intuito de levantar os dados econômicos desta, para que após a análise destes dados, seja possível realizar tomadas de decisões importantes para a condução da propriedade, podendo definir o seu futuro, bem como possibilitar o cálculo de alguns indicadores que darão uma visão geral da situação financeira do negócio principal da propriedade, que é o cultivo de soja, milho e trigo. Na figura 08 observa-se o balanço patrimonial da propriedade.

O balanço patrimonial, de acordo com Gitman (2010), oferece o demonstrativo dos resultados financeiros da propriedade rural considerando todas as suas receitas, despesas variáveis e fixas e o seu patrimônio, resultando no resultado líquido do período analisado. 
Figura 08 - Balanço patrimonial

\begin{tabular}{|c|c|c|c|c|c|c|c|}
\hline & \multicolumn{3}{|l|}{ ATIVO } & \multicolumn{4}{|c|}{ PASSIVO } \\
\hline & CIRCULANTE & & & & CIRCULANTE & & \\
\hline 1. & Caixa/banco & $\mathrm{RS}$ & $25.000,00$ & 1. & Empréstimo de Custeio & $\mathrm{RS}$ & - \\
\hline 2. & Aplicação financeiro & $\mathrm{RS}$ & - & 2. & Emprestimo de investimentc & RȘ & $8.650,00$ \\
\hline 3. & Cademeta de poupança & & & 3. & Contas à pagar & $\mathrm{R} \$$ & $15.061,62$ \\
\hline 4. & Contas à rece ber & & & & & & \\
\hline 5. & Produtos para venda & RS & $498.691,62$ & & & & \\
\hline 6. & animais para venda & RȘ & $15.000,00$ & & & & \\
\hline 7. & culturas anuais & RȘ & $21.600,00$ & & & & \\
\hline \multirow[t]{7}{*}{8.} & Insumos estocados & RȘ & $20.700,00$ & & & & \\
\hline & TOTAL DO CIRCULANTE & $\mathrm{R} \$$ & $580.991,62$ & & TOTAL CIRCULANTE & $\mathrm{R} \$$ & $23.711,62$ \\
\hline & REALIZÁVEL A LONGO PRAZO & & & & EXIG ÍVEL À LONGO PRAZO & & \\
\hline & Contas a rece ber (+365 dias) & & & 1. & Emprestimo e investimento & RȘ & - \\
\hline & Estoque de animais & & & 2. & Contas a Pagar & $\mathrm{R} \$$ & $60.246,48$ \\
\hline & TOTAL REAUZÁVEL A LONGO PRAZO & $\mathrm{RS}$ & - & & TOTAL DO EXIGÍVELA LP. & $R \$$ & $60.246,48$ \\
\hline & FIXO & & & & & & \\
\hline 1. & Máquinas, mot, veículo e equipameı & RȘ & $937.500,00$ & & TOTAL PASSIVO & R\$ & $83.958,10$ \\
\hline 2. & Benfeitorias e construções & R\$ & $234.000,00$ & & & & \\
\hline 3. & Terras & $\mathrm{R} \$$ & $3.716 .396,55$ & & & & \\
\hline 4. & Animais produtores & $\mathrm{RS}$ & $4.775,00$ & & & & \\
\hline 5. & Outros Investimentos & & & & & & \\
\hline 6. & \multicolumn{3}{|l|}{ Insumos estocad os para investimento } & & & & \\
\hline 7. & Animais de serviço & & & & & & \\
\hline \multirow[t]{3}{*}{8.} & Culturas e pastagens perenes & & & & & & \\
\hline & TOTAL FIXO & $\mathrm{R} \$$ & $4.892 .671,55$ & & PATRIMÔNIO ÚQUIDO & $\mathrm{R} \$$ & $5.389 .705,07$ \\
\hline & ATIVO TOTAL & $\mathrm{RST}$ & $5.473 .663,17$ & & & & \\
\hline
\end{tabular}

Fonte: Kreutz; Jeziorski; Silva; Meller (2019)

Com base nos dados do balanço patrimonial, foi possível concluir que o Grau de Endividamento da propriedade é de $1,53 \%$, isso significa que para cada $R \$ 100,00$ que a propriedade tem de patrimônio, existe uma dívida $R \$ 1,53$. Esse índice é considerado muito bom.

Como visto, o cultivo de grãos na propriedade é a principal atividade e fonte de renda. Os custos totais de cada cultura são formados pelos custos fixos somados aos custos variáveis de cada cultura, conforme apresentado na figura 09. 
Figura 09 - Custos totais das culturas

\begin{tabular}{|c|c|c|c|c|c|c|}
\hline CUSTOS TOTAIS & \multicolumn{2}{|c|}{ soja } & \multicolumn{2}{|c|}{ milho } & \multicolumn{2}{|c|}{ trigo } \\
\hline Depreciaçao & $\mathrm{RSS}$ & $101.041,42$ & $\mathrm{R} S$ & $4.024,19$ & $\mathrm{R} \$$ & $51.119,78$ \\
\hline Combustivel & $\mathrm{RS}$ & $14.365,22$ & $\mathrm{RS}$ & 649,28 & $\mathrm{RS}$ & $7.385,51$ \\
\hline Manutençao & $\mathrm{RS}$ & $8.861,54$ & $\mathrm{RS}$ & 400,52 & $\mathrm{RS}$ & $4.555,93$ \\
\hline Filtros e Lubrificantes & RS & $1.436,52$ & $\mathrm{RS}$ & 64,93 & RS & 738,55 \\
\hline Custos Variáveis & $\mathrm{RS}$ & $184.003,89$ & $\mathrm{RS}$ & $12.355,20$ & $\mathrm{RS}$ & $102.728,08$ \\
\hline Arrendamentos & $\mathrm{R} \$$ & $58.707,57$ & $\mathrm{RS}$ & $2.653,45$ & $\mathrm{R} \$$ & $30.182,99$ \\
\hline Custo Total /HÁ & $\mathbf{R} \$$ & $2,081,45$ & $\mathrm{R} \$$ & 2518,44 & $\mathbf{R} \$$ & $2.161,66$ \\
\hline
\end{tabular}

Fonte: Kreutz; Jeziorski; Silva; Meller (2019)

Analisando a figura 09, pode-se concluir que a cultura que teve o maior custo total foi o milho, com o valor de $\mathrm{R} \$ 2.518,44$ por hectare, seguido pela cultura do trigo, com valor de $\mathrm{R} \$ 2.161,66$ e, a cultura que apresentou o menor custo total, foi a soja, com custo total de $R \$ 2.081,45$.

A margem bruta refere-se a receita bruta de cada cultura, descontados os custos totais. Conforme demonstrado na figura 10, podemos observar que a cultura da soja é a que apresenta a maior margem bruta entre as culturas que são implantadas na propriedade, chegando a $46 \%$ na safra $2018 / 2019$, ou seja, para cada $R \$ 100,00$ investidos houve um retorno de $\mathrm{R} \$ 146,00$.

A cultura do milho na safra 2018/2019, apresentou margem bruta de 24\%, ou seja, para cada $R \$ 100,00$ investidos houve um retorno de $R \$ 124,00$. Já, a cultura do trigo, na safra 2018 apresentou margem bruta negativa de - 47\%, sendo que a cada $R \$$ 100,00 investidos apenas retornou $R \$ 53,00$.

Figura 10 - Margem bruta das culturas

\begin{tabular}{|c|c|c|c|c|c|c|}
\hline CULTURA & \multicolumn{2}{|c|}{ RECEITA BRUTA } & CUSTO TOTAL & \multicolumn{2}{|c|}{ MARGEM BRUTA } & $\mathrm{MB}(\%)$ \\
\hline Soja & $\mathrm{R} \$$ & $676.332,00$ & 368416,65 & $\mathrm{R} \$$ & $307.915,35$ & $46 \%$ \\
\hline Trigo & $\mathrm{R} \$$ & $134.201,20$ & 196711,06 & $-R \$$ & $62.509,86$ & $-47 \%$ \\
\hline Milho & $\mathrm{R} \$$ & $26.342,40$ & 20147,52 & $\mathrm{R} \$$ & $6.194,88$ & $24 \%$ \\
\hline TOTAL & $\mathrm{R} \$$ & $836.875,60$ & 585275,23 & $\mathrm{R} \$$ & $251.600,37$ & $30 \%$ \\
\hline
\end{tabular}

Fonte: Kreutz; Jeziorski; Silva; Meller (2019) 
Através da análise econômica da criação de ovinos, verificou-se que a atividade não se mostra vantajosa, pois não se tem resultado positivo na produção, mas sim negativo, ao que na análise econômica remete a exclusão da atividade e, possivelmente, remete a substituição para o cultivo de grãos que tem resultado significativo de produção, além de se dedicar a produção de somente um sistema.

\section{CONCLUSÃO}

De acordo com as atividades realizadas na propriedade, juntamente com o levantamento de dados feito com os sócios-proprietários, levando em consideração as hipóteses e o problema, pôde-se obter algumas considerações.

Quanto à hipótese que refere-se aos indicadores de alta fertilidade do solo, esta não foi confirmada devida a baixa fertilidade do solo das glebas analisadas, pois se encontram com pH ácido e níveis altos de alumínio, trazendo, assim, limitações de produtividade por acides e intoxicação por Al.

Considerando um dos maiores motivo de degradação do solos, ocasionando a perda de nutrientes e, sobretudo, um desequilíbrio na estrutura do solo, a erosão hídrica, deve ser levada a sério, pois com ela a palhada e a solução do solo contendo nutrientes vitais para o desenvolvimento pleno das culturas são levados pela água. Por esse motivo, a hipótese de que haveria prática de conservação de solo na propriedade não se confirma, pois esta ocorre em apenas duas glebas pelo método de curvas de níveis e, mesmo nestas áreas, é fácil visualização da falta de manutenção dos terraços, porque verifica-se o escorrimento superficial nas glebas. $O$ restante das áreas não possuem nenhum tipo de contenção e rotação de culturas, o cultivo realizado na propriedade é sucessão de culturas de Trigo/Soja e uma pequena área de milho para subsistência.

Quanto à hipótese de níveis dos nutrientes fósforo e potássio analisados através da interpretação da análise de solo, chegou-se à conclusão que variam conforme as glebas. Então, foi possível avaliar as glebas Lanzanova, que possuem nível alto do nutriente K, enquanto a gleba pastagem, possui nível médio. Quando comparado aos 
níveis de $\mathrm{P}$, as glebas Lanzanova 1 e pastagem tem um nível alto e, a lanzanova 2, atinge o teor de nível médio, confirmando a hipótese em questão, que a disponibilidade de nutrientes favorece o desenvolvimento da cultura auxiliando no aumento da produtividade.

A propriedade desenvolve em sua maior parte o cultivo de grãos e, em pormenores, a subsistência. Uma das hipóteses era sobre as atividades desenvolvidas na propriedade, em sua diversidade de cultivo. Segundo os cálculos feitos, estes geram resultados positivos em termos de lucratividade, pois apesar de se ter números negativos no cultivo de trigo safra $2018 / 19$, os outros grãos, como soja e milho, apresentaram bons números, mostrando que realmente há liquidez das contas, além de cobrir os custos com a produção de ovinos que se tem na propriedade.

O grupo familiar participa, por meio da igreja e da comunidade em que está inserido, de eventos que ocorrem na localidade, além de ter boa relação de amizade para com os outros sócios, bem como com os donos do comércio local com os quais realizam negócios da propriedade e seus particulares, então, confirma-se a hipótese de se ter uma relação externa com a comunidade em que está inserido.

A hipótese referente à sucessão familiar futura das atividades da propriedades se confirma como exposto, pois se almeja que o filho de Maria, que já trabalha na propriedade, e o filho de Abílio, que busca por resolução dos proprietários voltar para a propriedade depois de concluir a graduação.

Referente às mulheres que lá residem, a divisão do trabalho se dá pelo cultivo da horta, para ter alimentos básicos no dia a dia, e encargos da casa. Os homens, ficam encarregados de prestar os serviços referente ao cultivo de grãos e manejo de animais para a subsistência, limpeza e organização do maquinário agrícola.

Retomando o problema da pesquisa: "Como as variáveis técnicas, econômicas, sociais e ambientais da propriedade analisada auxiliam na geração de renda e subsistência?" Dentre as informações coletadas para responder a esta problemática, se tornou necessário analisar os itens descritos no diagnóstico da propriedade e, com base nessas informações, pode-se confirmar que esta propriedade atende aos 
requisitos técnicos, econômicos, sociais e ambientais, oportunizando a geração de renda á família mantendo as oportunidades de lazer e participação com a sociedade.

Portanto, conclui-se que, baseado em todo o estudo acima, a propriedade estudada apresenta viabilidade, garantindo a sustentabilidade, com incentivo à sucessão familiar.

\section{REFERÊNCIAS}

ANDRIOLI, Antônio Inácio (org.). Tecnologia e agricultura familiar: uma relação de educação. ljuí. Ed. Unijuí. 2009. ISBN 9788574298528.

BONA, Fabiano Daniel de; Mori, Cláudia de; WIETHÖLTER, Sirio. Manejo nutricional da cultura do trigo. Informações agronômicas no 154. International plant nutrition institute-Brasil. 2016. ISSN 23115904.

BRANDÃO, Thales. Sucessão familiar. [Online]. 2015. Disponível em <http://www.ibe.edu.br/sucessao-familiar/>. Acessado em 09 mar. 2019.

BRASIL. 2012. Lei no 12.651, de 25 de maio de 2012. Dispõe sobre a proteção da vegetação nativa; altera as Leis ํㅜ 6.938, de 31 de agosto de 1981, 9.393, de 19 de dezembro de 1996, e 11.428, de 22 dezembro de 2006; revoga as Leis nos 4.771, de 15 de setembro de 1965, e 7.754, de 14 abril de 1989, e a Medida Provisória no 2.166 67, 24 de agosto de 2001; e dá outras providências. Brasília: DF: Diário Oficial da União, p. 1, 28/05. Seção 1 .

BROCH, Dirceu Luiz; RANNO, Sidnei Kuster. Fertilidade do Solo, Adubação e Nutrição da Cultura da Soja. Tecnologia e Produção: Soja e Milho 2011/2012. Maracaju: Fundação MS. 2012.

CARMO, Raquel Mendes do; COLOGNESE, Silvio. Qualificação e permanência do agricultor familiar no campo: a casa familiar rural do município de Candói - PR. Revista Eletrônica Multidisciplinar. V. 1. N. 1. Pitanga: UCP. 2010. 
CUNHA, Fernando França da; LEAL, Aguinaldo José Freitas; ROQUE, Cassiano Garcia.. Planejamento de sistemas de terraceamento utilizando o software Terraço 3.0. Brazilian Geographical Journal: Geosciences and Humanities research medium, v. 2, n. 1. Uberlândia: UFU. Jan/Jun. p. 182-196, 2011.

FERNANDES, S.; SALAMONI, G. Proposta metodológica para diagnóstico socioeconômico e ambiental: uma abordagem sistêmica e integrada do espaço agrário. In: Anais do XXI Encontro Nacional de Geografia Agrária, MG: UFU, 2012.

GARCIA, Rodrigo Arroyo. Diversificação do sistema produtivo: estratégia para superar entraves da sucessão de culturas. Revista A granja. [Online]. 2017. Disponível em <https://www.embrapa.br/busca-de-noticias/-/noticia/14364329/artigo--diversificacao-do-sistema-produtivo-estrategia-para-superar-entraves-da-sucessaode-culturas>. Acessado e 30 mar. 2019.

GITMAN, Lawrence. 2010. Princípios de administração financeira. 12. Ed., São Paulo: Pearson.

GRISA, Catia; SCHNEIDER, Sergio. Três gerações de políticas públicas para a agricultura familiar e formas de interação entre sociedade e estado no Brasil. Revista de Economia e Sociologia Rural. v. 52. Suppl. Piracicaba: SOBER Fev. pp. 125-146. 2014.

KLEIN, Marcelo A; ROSA Marcelo B. Adequação de propriedades de agricultores familiares à legislação ambiental: a educação ambiental como mitigadora do processo. Santa Maria, RS: UFSM. 2011.

REUNIÃO TÉCNICA ANUAL DO MILHO, 62ㅜ; REUNIÃO TÉCNICA ANUAL DO SORGO, 45․ Indicações técnicas para o cultivo de milho e de sorgo no Rio Grande do Sul: safras 2017/2018 e 2018/2019. Pelotas: Embrapa clima temperado. 2017.

SANTIAGO, Emerson.Agricultura de subsistência. Brasil Info Escola. 2011. 
SILVA, Edson Cordeiro da. Como administrar o fluxo de caixa das empresas. São Paulo: Atlas. 2005.

SOUZA, Reginaldo Teodoro de; PALLADINI, Luiz Antonio. Sistema de produção de uva de mesa do Norte de Minas Gerais. Sistema de Produção 11. Bento Gonçalves: Embrapa Uva e Vinho. 2005.

TESCHE, Rubens Wladimir; MACHADO, João Armando Dessimon. As Relações de Reciprocidade e Redes de Cooperação no Desempenho Socioeconômico da Agricultura Familiar. Emater/RS-Ascar. 2007.

THOEH, Frederick, R; THOMPSON, Louis, M. Solos e fertilidade do solo. 5 Ed São Paulo. 2007.

VALLE, Ezequiel Rodrigues. (Coord.). Boas práticas agropecuárias: Bovinos de corte. Campo Grande: Embrapa Gado de Corte. 84 p. 2007. ISBN 85-297-0203-4.

Enviado: Novembro, 2021.

Aprovado: Fevereiro, 2022. 